\title{
Determination of sesame oil, rice bran oil and pumpkin seed oil in ternary mixtures using FTIR spectroscopy and multivariate calibrations
}

\author{
${ }^{1,2}$ Irnawati, ${ }^{1}$ Riyanto, S., ${ }^{1}$ Martono, S. and ${ }^{1,3^{*}}$ Rohman, A \\ ${ }^{1}$ Department of Pharmaceutical Chemistry, Faculty of Pharmacy, Universitas Gadjah Mada, Yogyakarta \\ ${ }^{2}$ Faculty of Pharmacy, Universitas Halu Oleo Kendari, Souteast Sulawesi 93232 Indonesia. \\ ${ }^{3}$ Institute of Halal Industry and Systems, Universitas Gadjah Mada, Yogyakarta 55281 Indonesia
}

Article history:

Received: 18 July 2019

Received in revised form: 15

August 2019

Accepted: 17 August 2019

Available Online: 26 August

2019

Keywords:

FTIR spectra,

Pumpkin seed oil,

Rice bran oil,

Sesame oil,

Multivariate calibrations

\section{DOI:}

https://doi.org/10.26656/fr.2017.4(1).260

\begin{abstract}
Pumpkin seed oil (PSO), rice bran oil (RBO), sesame oil (SEO) are considered as functional oils due to its biological activities which are beneficial to human health, as a consequence, these oils had the higher price. This attracted unethical players to blend these oils with lower price oils, therefore, its authentication by analysis of purity levels of oils is very important. This study highlighted the potential application of FTIR spectroscopy and multivariate calibrations for analysis of PSO, RBO, and SEO in ternary mixtures. Individual FTIR spectra of studied oils as well as in ternary mixtures with certain compositions were scanned and pre-processed. Two multivariate calibrations of principle component regression (PCR) and partial least square regression (PLSR) were compared and used to build the prediction models at optimized FTIR spectra regions. The selection of multivariate calibrations, wavenumbers region, and FTIR spectra modes was based on the statistical parameters of highest $\mathrm{R}^{2}$ and lowest values of root mean square error of calibration (RMSEC) and root mean square error of prediction (RMSEP). The results showed that PLSR using second derivative FTIR spectra at wavenumbers region of 3100-2750 and 1500-663 $\mathrm{cm}^{-1}$ was used to predict the levels of PSO in ternary mixtures with $\mathrm{RBO}$ and SEO with $\mathrm{R}^{2}>0.99$ in calibration and validation models along with RMSEC value of $0.0054 \%$ and RMSEP of $0.0179 \%$. FTIR spectra using the second and first derivatives at wavenumbers of $3100-650 \mathrm{~cm}^{-1}$ were used for prediction of RBO and SEO in ternary mixture with PSO, respectively. It can be concluded that FTIR spectra combined with PLSR at certain wavenumbers region are accurate as indicated by high $\mathrm{R}^{2}$ values and precise as indicated by low values of RMSEC and RMSEP for analysis of $\mathrm{PSO}, \mathrm{RBO}$ and SEO in ternary mixtures.
\end{abstract}

\section{Introduction}

Sesame oil (SEO) has a high price in the fats and oils industry due to delightful odor, delicious taste, and nutritional value (Ramesh et al., 2005). It can be used for preparing several foods including soup, salad, forcemeat and refreshments, which can promote the appetite ( $\mathrm{Ji}$ et al., 2019). SEO is believed to have several biological activities including reducing blood glucose and increasing antioxidant levels in streptozotocin-induced diabetic rats (Ramesh et al., 2005), anticancer through inhibiting proliferation and inducing apoptosis (Yoshiyukimiyahara et al., 2001), antihypertension (Nakano, Ogura, Miyakoshi et al., 2006; Miyawaki et al., 2009), antioxidant (Nakano, Kwak, Fujii et al., 2006), and analgesic (Nahar and Rokonuzzaman, 2009), and autoimmune encephalomyelitis inhibitor in C57BL/6 mice (Mosayebi et al., 2007).
Pumpkin seed oil (PSO) has been reported to contain phytosterols, phenolic compounds, antioxidants, tocopherols, and small levels of carotenoids responsible to some biological activities which are beneficial to human health (Cuco et al., 2019) including prevention of gastric, breast, colorectal and lung cancers (Elfiky et al., 2012), retardation of hypertension progression antihypertension (Zuhair et al., 2000), prevention of prostate disease, mitigation of hypercholesterolemia and arthritis, alleviation of diabetes mellitus by enhancing hypoglycaemic activity, reduction of bladder and urethral pressure (Fruhwirth et al., 2003; Fu et al., 2006), improving bladder compliance and urinary disorder in Human overactive bladder (Nishimura et al., 2014), and offering good antioxidant sources (Nawirska-Olszan' ska et al., 2013; Naziri et al., 2016).

Rice bran oil (RBO), one of the high valuable oils 
recommended to be consumed by the World Health Organization (WHO), is commonly consumed in Asian countries like India, Japan, China, Korea, and Indonesia (Liu et al., 2019), and is believed to contain some phytochemicals having beneficial effects to human health (Ghosh, 2007). RBO contains unsaturated fatty acids, especially oleic acid and linoleic acid accounting of $45 \%$ and $33 \%$, respectively. Besides, RBO is also rich in multiple dietary phytochemicals including tocopherols (tocophenol and tocotrienol), squalene, phytosterols, polyphenols, and $\gamma$-oryzanol (Patel and Naik, 2004). These bioactive compounds are responsible for biological activities such as antioxidant (Thanonkaew et al., 2012), anti-inflammatory agent (Rao et al., 2016), and for the treatment of cardiovascular disease, atherosclerosis and hyperlipidemia (Wilson et al., 2007).

Fourier transform infrared (FTIR) spectroscopy offered an official standard method because this technique could be used to analyze analytes as a whole (Rohman and Che Man, 2011a), not through specific components composed edible fats and oils like gas chromatography for analysis of derivatized fatty acids as methyl esters and liquid chromatography for analysis of triglyceride composition and sterol composition. Therefore, FTIR spectroscopy is considered an ideal method for analysis of edible fats and oils. In complex mixtures, FTIR spectroscopy with the aid of multivariate calibration has been successfully used for quantitative analysis of complex systems. These include analysis of virgin coconut oil in the ternary mixture with palm oilolive oil as well as olive oil in the mixture with soybean oil-corn oil (Rohman and Che Man, 2011a), analysis of olive oil in quaternary mixture with grape seed oil, rice bran oil and walnut oil (Rohman and Che Man, 2011b) and analysis of lard in quaternary mixtures with body fats of lamb, chicken and cow (Rohman and Che Man, 2010). In this study, the combination of FTIR spectroscopy and multivariate analysis (calibration in multivariate modes and discriminant analysis) for the determination of three functional edible oils of SEO, PSO, and RBO. The selection of these three oils was based on the similarity in terms of FTIR spectra as analyzed using chemometrics of principal component analysis (PCA) exploiting the absorbance values as variables (Irnawati et al., 2020).

\section{Materials and methods}

\subsection{Materials}

Pumpkin seed oil (PSO), sesame oil (SEO) and rice bran oil (RBO) were purchased from several markets in Yogyakarta, Indonesia. The composition of the fatty acids of PSO, SEO, and RBO was analyzed using gas chromatography with flame ionization detector as derivate of fatty acid methyl ester (FAME) using 37 FAME standards. The composition of fatty acids of PSO, SEO and RBO were in accordance with those listed in Codex Alimentarius Commission (2010). The solvents and reagents used were of pro-analytical grade.

\subsection{Preparation of calibration and validation samples}

For quantitative analysis purposes, a series of calibration and validation (prediction) samples with known concentrations of PSO, SEO and RBO were prepared. For making calibration samples, numerous samples consisting of PSO in ternary mixtures with SEO and $\mathrm{RBO}$ at concentration ranges of $0-100.0 \%$ volume/ volume as in Table 1 were prepared. The oil levels in ternary systems were selected randomly with the assistance of Excel software (Microsoft Inc., USA). For preparing validation samples, a series of different samples was preparing in the concentration ranges covered by calibration samples. All samples were analyzed using FTIR spectrophotometer.

Table 1. The composition of rice bran oil (RBO), sesame oil (SEO) and pumpkin seed oil (PSO) used for modelling the simultaneous analysis of studied oils

\begin{tabular}{cccc}
\hline \multirow{2}{*}{ Sample No } & \multicolumn{3}{c}{ Percentage of studied oils (\%, volume/volume) } \\
\cline { 2 - 4 } & RBO & SeO & PSO \\
\hline 1 & 23 & 34 & 42 \\
2 & 5 & 0 & 95 \\
3 & 18 & 2 & 80 \\
4 & 46 & 44 & 10 \\
5 & 25 & 28 & 47 \\
6 & 26 & 3 & 71 \\
7 & 36 & 41 & 23 \\
8 & 26 & 19 & 55 \\
9 & 15 & 46 & 39 \\
10 & 40 & 1 & 59 \\
11 & 31 & 24 & 45 \\
12 & 25 & 43 & 32 \\
13 & 23 & 27 & 50 \\
14 & 18 & 46 & 36 \\
15 & 12 & 8 & 80 \\
16 & 34 & 13 & 53 \\
17 & 39 & 49 & 12 \\
18 & 18 & 24 & 58 \\
19 & 23 & 26 & 51 \\
20 & 27 & 18 & 55 \\
\hline
\end{tabular}

\subsection{FTIR spectra acquisition}

The acquisition of FTIR spectra of studied samples was performed using FTIR spectrometer (Thermo Scientific Nicolet iS10, Madison, WI), controlled with the operating Omnic software. The measurements were done in mid infrared region of $4000-650 \mathrm{~cm}^{-1}$ with 32 scannings and the resolution was $8 \mathrm{~cm}^{-1}$ using horizontal 
attenuated total reflectance (HATR) composed of $\mathrm{ZnSe}$ crystal. All FTIR spectra were corrected against FTIR spectrum of air as background. After every scan, a new reference air background spectrum was taken. These spectra were recorded as absorbance values at each data point in triplicate.

\subsection{Chemometrics analysis}

Chemometrics analysis including multivariate calibration and discriminant analysis was performed using TQ Analyst software version 9 (Thermo Fisher Scientific, Inc.). For quantification, multivariate calibrations used were partial least square regression (PLSR) and principle component regression (PCR). The principle component analysis was carried out using software Minitab version 17 (Minitab Inc., USA).

\section{Results and discussion}

FTIR spectra could be effective means for analysis of complex samples due to its capability to provide several analytical signals (peaks and shoulders) which could be exploited as dependent variables in quantitative analysis using calibration models. In this study, the sampling technique used was attenuated total reflectance in which the evaluated samples were directly placed into ATR crystals without any addition of solvents. Therefore, FTIR-ATR spectroscopy techniques are taken into account as green analytical chemistry. Combined with multivariate calibrations of principle component regression (PCR) and partial least square regression (PLSR), FTIR spectra could be used as powerful quantitative analytical techniques (Rohman and Che Man, 2011a). Figure 1 the FTIR spectra-ATR of evaluated oils (SEO, PSO and RBO) without any pretreatment of spectral data in the regions of 4000 and 650 $\mathrm{cm}^{-1}$.

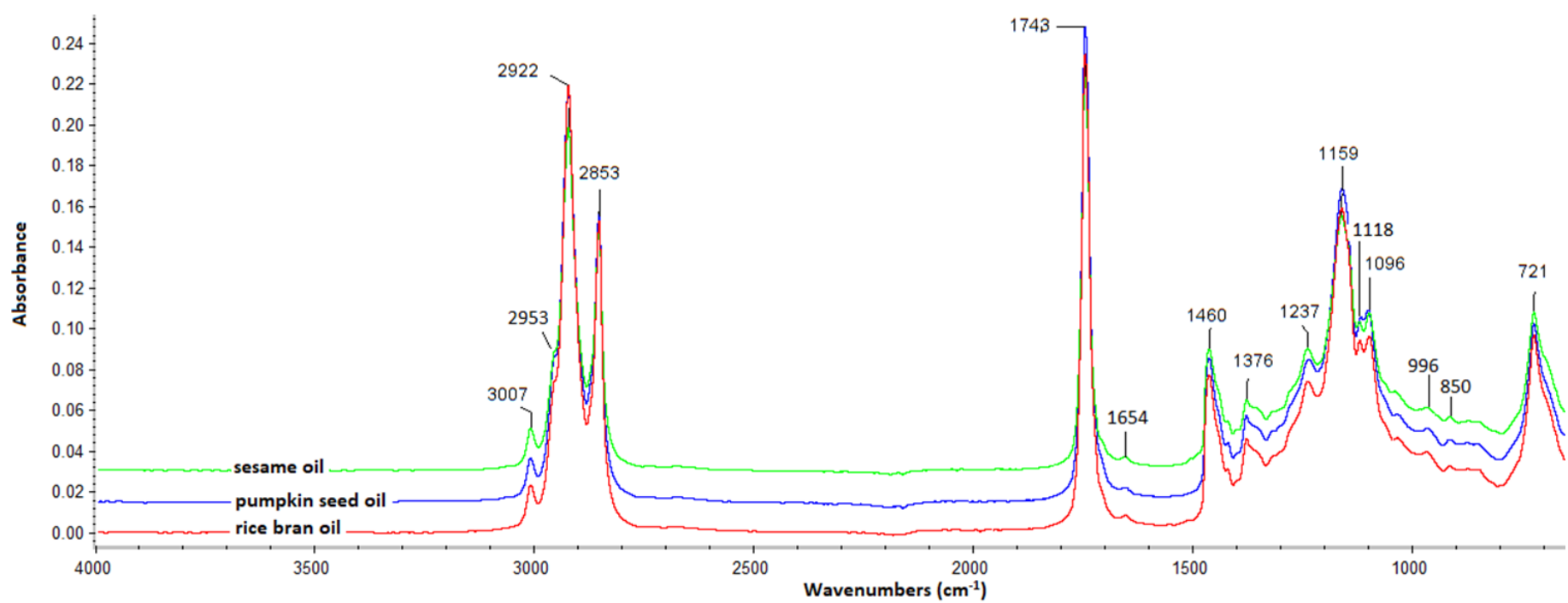

Figure 1. FTIR-attenuated total reflectance spectra of sesame oil, pumpkin seed oil, and rice bran oil at mid infrared region (4000 $-650 \mathrm{~cm}^{-1}$ ) scanned with resolution of $8 \mathrm{~cm}^{-1}$ and number of scanning of 32 .
The selection of PSO, SEO and RBO in ternary mixtures was based on the similarity of these three FTIR spectra based on principal component analysis (PCA). These oils had the similar score plot both in the first principle components $(\mathrm{PC} 1)$ and the second principle component (PC2), therefore they are similar in variables used in PCA (Irnawati et al., 2020).

For interpretation of FTIR spectra of studied oils, the absorption band at $3007 \mathrm{~cm}^{-1}$ corresponds to the cis $=\mathrm{CH}$ stretching vibration, while bands with strong intensities at 2953,2953 and $2853 \mathrm{~cm}^{-1}$ arise from the vibrations of $\mathrm{C}-\mathrm{H}$, namely asymmetric stretching of $-\mathrm{CH}\left(\mathrm{CH}_{3}\right)$, asymmetric stretching of $-\mathrm{CH}\left(\mathrm{CH}_{2}\right)$-, and symmetric stretching of $-\mathrm{CH}\left(\mathrm{CH}_{3}\right)$, respectively. The strong band at wavenumbers of $1743 \mathrm{~cm}^{-1}$ comes from stretching vibration of $\mathrm{C}=\mathrm{O}$ in triglyceride. The weak band at 1654 $\mathrm{cm}^{-1}$ is due to the vibration of alkene group $(\mathrm{C}=\mathrm{C})$ from unsaturated fatty acids contained in studied oils especially oleic and linoleic acids, while the bands with strong and medium intensities located at 1460 and 1378 $\mathrm{cm}^{-1}$ arise from scissoring (bending) vibration of $-\mathrm{CH}_{2}$ and $-\mathrm{CH}_{3}$, respectively (Armenta et al., 2007). The band at $1237 \mathrm{~cm}^{-1}$ originates from stretching vibrations of C-C bonds of belonging to hydrocarbon skeletal. Bands at wavenumbers range between 1159-1096 were corresponding to $\mathrm{C}-\mathrm{O}$ stretching vibration, while the band at $996 \mathrm{~cm}^{-1}$ is due to vibration of trans $=\mathrm{C}-\mathrm{H}$. The last band located at 850 and $722 \mathrm{~cm}^{-1}$ represent bending (rocking mode) vibration of methylene $\left(-\mathrm{CH}_{2}\right)$ and bending vibration (out of plane) of cis-disubstituted olefin (Sim and Ting, 2012). The FTIR-ATR spectra exhibited that no specific fingerprint peaks to differentiate among these three oils, as a consequence, differences in the peak intensity were investigated for simultaneous analysis of studied oils.

To perform quantitative analysis of SEO, PSO and 
RBO simultaneously, PCR and PLSR were compared using absorbance values at specific wavenumbers as independent variables. This absorbance was combined to get what called with "principle components" or factors and then these factors were regressed toward actual values of studied oils. The selection of wavenumbers used relied on the variations (in terms of peak intensities) existed among oils. Besides, the derivative spectra were also prepared and compared its performance with normal spectra. The spectra derivatization could take advantage of resolving the overlapping peaks, but the sensitivity was decreased.

Table 2 shows the statistical results expressed with coefficient of determination $\left(\mathrm{R}^{2}\right)$ in the calibration and validation models, RMSEC and RMSEP values obtained during optimization of FTIR spectra for determination of SEO in ternary mixtures with PSO and RBO using normal and derivative spectra (first- and second derivatives) at specific wavenumbers region along with multivariate calibration types. PLSR at combined wavenumbers region of 3100-2750 and 1500-663 $\mathrm{cm}^{-1}$ was finally used to predict the contents of SEO, PSO and RBO as indicated by highest $\mathrm{R}^{2}(0.9997$ and 0.9964 in calibration and validation models) and by lowest values of RMSEC of $0.0054 \%$ and RMSEP of $0.0179 \%$. The low value of RMSEC and RMSEP indicated that the developed models were precise enough, while high $R^{2}$ values $(>0.99)$ expressed the accurate models. Therefore, FTIR spectra could be used to predict SEO in ternary mixtures with PSO and RBO in unknown samples.

Figure 2[A] reveals the scatter plot describing the relationship between actual values of PSO in ternary mixtures with RBO and SEO and FTIR predicted values PLSR at combined wavenumbers region of $3100-2750$

Table 2. The performance of multivariate calibrations of principle component regression (PCR) and partial least square regression (PLSR) for quantitative analysis of pumpkin seed oil (PSO) in ternary mixture with sesame oil and rice bran oil

\begin{tabular}{|c|c|c|c|c|c|c|}
\hline \multirow{2}{*}{$\begin{array}{l}\text { Multivariate } \\
\text { calibrations }\end{array}$} & \multirow{2}{*}{ Wavenumber $\left(\mathrm{cm}^{-1}\right)$} & \multirow{2}{*}{ Spectra } & \multicolumn{2}{|c|}{ Calibration } & \multicolumn{2}{|c|}{ Validation } \\
\hline & & & $\mathrm{R}^{2}$ & RMSEC & $\mathrm{R}^{2}$ & RMSEP \\
\hline \multirow{18}{*}{ PCR } & \multirow{3}{*}{$3100-663$} & normal & 0.9979 & 0.0139 & 0.996 & 0.0213 \\
\hline & & derivative 1 & 0.9987 & 0.011 & 0.9984 & 0.0129 \\
\hline & & derivative 2 & 0.9945 & 0.0223 & 0.9935 & 0.0279 \\
\hline & \multirow{3}{*}{$1800-663$} & normal & 0.9982 & 0.0126 & 0.9964 & 0.0192 \\
\hline & & derivative 1 & 0.9988 & 0.0103 & 0.998 & 0.0139 \\
\hline & & derivative 2 & 0.994 & 0.0232 & 0.9944 & 0.0262 \\
\hline & \multirow{3}{*}{$3100-2750$} & normal & 0.9932 & 0.0246 & 0.9913 & 0.0297 \\
\hline & & derivative 1 & 0.9817 & 0.0272 & 0.9892 & 0.0337 \\
\hline & & derivative 2 & 0.9388 & 0.073 & 0.9517 & 0.0707 \\
\hline & \multirow{3}{*}{$1500-663$} & normal & 0.9988 & 0.0102 & 0.9983 & 0.0131 \\
\hline & & derivative 1 & 0.9984 & 0.0122 & 0.9966 & 0.0177 \\
\hline & & derivative 2 & 0.9913 & 0.0278 & 0.9882 & 0.0325 \\
\hline & \multirow{3}{*}{$3100-2750$ and $1800-663$} & normal & 0.9981 & 0.0129 & 0.9968 & 0.0325 \\
\hline & & derivative 1 & 0.9984 & 0.0121 & 0.9983 & 0.0187 \\
\hline & & derivative 2 & 0.9941 & 0.0229 & 0.9946 & 0.0134 \\
\hline & \multirow{3}{*}{$3100-2750$ and $1500-663$} & normal & 0.997 & 0.0163 & 0.9963 & 0.0219 \\
\hline & & derivative 1 & 0.9984 & 0.0119 & 0.9971 & 0.0165 \\
\hline & & derivative 2 & 0.9941 & 0.0231 & 0.9904 & 0.0293 \\
\hline \multirow{18}{*}{ PLSR } & \multirow{3}{*}{$3100-663$} & normal & 0.998 & 0.0135 & 0.996 & 0.0225 \\
\hline & & derivative 1 & 1 & 0.0013 & 0.9986 & 0.0115 \\
\hline & & derivative 2 & 1 & 0.0012 & 0.9963 & 0.0216 \\
\hline & \multirow{3}{*}{$1800-663$} & normal & 0.9984 & 0.0119 & 0.997 & 0.0172 \\
\hline & & derivative 1 & 0.9996 & 0.0063 & 0.9978 & 0.0143 \\
\hline & & derivative 2 & 1 & 0.002 & 0.9961 & 0.0208 \\
\hline & \multirow{3}{*}{$3100-2750$} & normal & 0.9946 & 0.0219 & 0.9933 & 0.0263 \\
\hline & & derivative 1 & 0.9969 & 0.0167 & 0.9902 & 0.0312 \\
\hline & & derivative 2 & 0.9948 & 0.0217 & 0.9418 & 0.0717 \\
\hline & \multirow{3}{*}{$1500-663$} & normal & 0.9992 & 0.0084 & 0.9982 & 0.0134 \\
\hline & & derivative 1 & 0.9995 & 0.0065 & 0.9979 & 0.0139 \\
\hline & & derivative 2 & 0.9983 & 0.0124 & 0.9933 & 0.0245 \\
\hline & \multirow{3}{*}{$3100-2750$ and $1800-663$} & normal & 0.9974 & 0.0153 & 0.9955 & 0.024 \\
\hline & & derivative 1 & 0.9987 & 0.0107 & 0.9987 & 0.0119 \\
\hline & & derivative 2 & 1 & 0.0012 & 0.9975 & 0.0182 \\
\hline & \multirow{3}{*}{$3100-2750$ and $1500-663$} & normal & 0.9994 & 0.007 & 0.9977 & 0.015 \\
\hline & & derivative 1 & 0.9995 & 0.0067 & 0.9984 & 0.0121 \\
\hline & & derivative 2 & 0.9997 & 0.0054 & 0.9964 & 0.0179 \\
\hline
\end{tabular}

*the selected condition was marked with bold. 
[A]

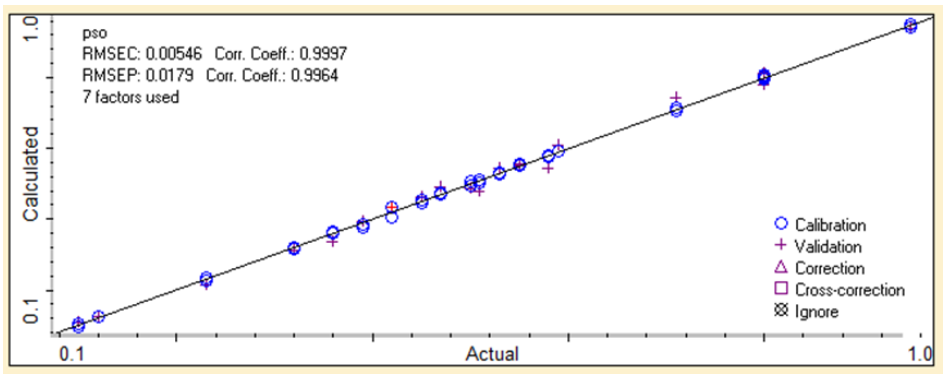

[B]

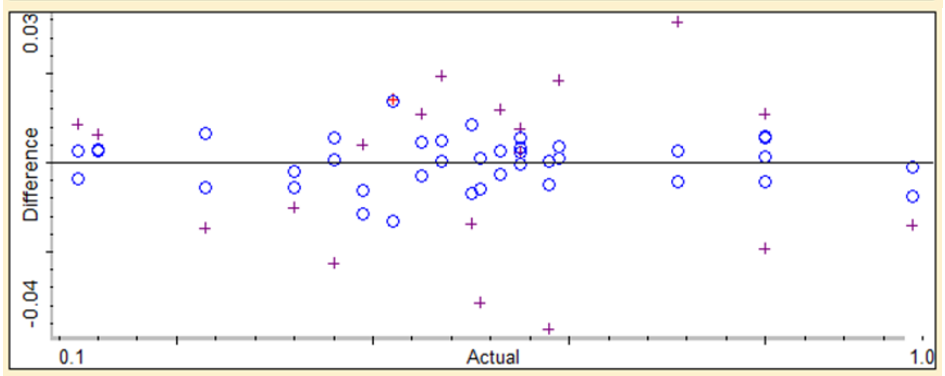

Figure 2. The PLS regression for relationship between actual values of pumpkin seed oil (PSO) in ternary mixtures with rice bran oil and sesame oil at combined wavenumbers region of 3100-2750 and 1500-663 $\mathrm{cm}^{-1}$ using the second derivative FTIR [A] along with residual analysis [B].

Table 3. The performance of multivariate calibrations of principle component regression (PCR) and partial least square regression (PLSR) for quantitative analysis of rice bran oil in ternary mixture with sesame oil and pumpkin seed oil (PSO)

\begin{tabular}{|c|c|c|c|c|c|c|}
\hline \multirow{2}{*}{$\begin{array}{l}\text { Multivariate } \\
\text { calibrations }\end{array}$} & \multirow{2}{*}{ Wavenumber $\left(\mathrm{cm}^{-1}\right)$} & \multirow{2}{*}{ Spectra } & \multicolumn{2}{|c|}{ Calibration } & \multicolumn{2}{|c|}{ Validation } \\
\hline & & & $\mathrm{R}^{2}$ & RMSEC & $\mathrm{R}^{2}$ & RMSEP \\
\hline \multirow{18}{*}{ PCR } & \multirow{3}{*}{$3100-663$} & normal & 0.9894 & 0.0143 & 0.9821 & 0.0303 \\
\hline & & derivative 1 & 0.9903 & 0.0136 & 0.987 & 0.0264 \\
\hline & & derivative 2 & 0.9758 & 0.0215 & 0.9617 & 0.0298 \\
\hline & \multirow{3}{*}{$1800-663$} & normal & 0.9829 & 0.0181 & 0.9741 & 0.0433 \\
\hline & & derivative 1 & 0.9847 & 0.0171 & 0.9784 & 0.034 \\
\hline & & derivative 2 & 0.9724 & 0.0229 & 0.9523 & 0.034 \\
\hline & \multirow{3}{*}{$3100-2750$} & normal & 0.9545 & 0.0293 & 0.9395 & 0.0365 \\
\hline & & derivative 1 & 0.95 & 0.0307 & 0.9559 & 0.0292 \\
\hline & & derivative 2 & 0.8236 & 0.0557 & 0.8384 & 0.056 \\
\hline & \multirow{3}{*}{$1500-663$} & normal & 0.9847 & 0.0171 & 0.9715 & 0.0255 \\
\hline & & derivative 1 & 0.9481 & 0.0312 & 0.924 & 0.0376 \\
\hline & & derivative 2 & 0.8303 & 0.0547 & 0.7833 & 0.0616 \\
\hline & \multirow{3}{*}{$3100-2750$ and $1800-663$} & normal & 0.988 & 0.0152 & 0.9797 & 0.0316 \\
\hline & & derivative 1 & 0.9883 & 0.015 & 0.9872 & 0.0285 \\
\hline & & derivative 2 & 0.973 & 0.0227 & 0.9525 & 0.0354 \\
\hline & \multirow{3}{*}{$3100-2750$ and $1500-663$} & normal & 0.9718 & 0.0232 & 0.9422 & 0.0344 \\
\hline & & derivative 1 & 0.9613 & 0.0271 & 0.9367 & 0.0346 \\
\hline & & derivative 2 & 0.8744 & 0.0476 & 0.8101 & 0.059 \\
\hline \multirow{18}{*}{ PLS } & \multirow{3}{*}{$3100-663$} & normal & 0.9952 & 0.0095 & 0.9794 & 0.0301 \\
\hline & & derivative 1 & 0.9986 & 0.0052 & 0.9902 & 0.0254 \\
\hline & & derivative 2 & 0.9999 & 0.0013 & 0.9821 & 0.0242 \\
\hline & \multirow{3}{*}{$1800-663$} & normal & 0.9898 & 0.014 & 0.9797 & 0.0416 \\
\hline & & derivative 1 & 0.9954 & 0.0094 & 0.9819 & 0.0332 \\
\hline & & derivative 2 & 0.986 & 0.0164 & 0.9682 & 0.032 \\
\hline & \multirow{3}{*}{$3100-2750$} & normal & 0.9662 & 0.0253 & 0.9537 & 0.032 \\
\hline & & derivative 1 & 0.9858 & 0.0165 & 0.9507 & 0.0336 \\
\hline & & derivative 2 & 0.9855 & 0.0167 & 0.8991 & 0.047 \\
\hline & \multirow{3}{*}{$1500-663$} & normal & 0.9893 & 0.0143 & 0.9733 & 0.0249 \\
\hline & & derivative 1 & 0.9741 & 0.0222 & 0.9591 & 0.0279 \\
\hline & & derivative 2 & 0.6951 & 0.0706 & 0.6734 & 0.0726 \\
\hline & \multirow{3}{*}{$3100-2750$ and $1800-663$} & normal & 0.9913 & 0.013 & 0.9788 & 0.0311 \\
\hline & & derivative 1 & 0.9937 & 0.011 & 0.9883 & 0.0269 \\
\hline & & derivative 2 & 0.998 & 0.0061 & 0.9829 & 0.0287 \\
\hline & \multirow{3}{*}{$3100-2750$ and $1500-663$} & normal & 0.9976 & 0.0068 & 0.9869 & 0.0277 \\
\hline & & derivative 1 & 0.9931 & 0.0116 & 0.9841 & 0.0181 \\
\hline & & derivative 2 & 0.7945 & 0.0596 & 0.7722 & 0.0624 \\
\hline
\end{tabular}

*the selected condition was marked with bold. 
Table 4. The statistical parameters of multivariate calibrations of principle component regression (PCR) and partial least square regression (PLSR) for quantitative analysis of sesame oil (SEO) in ternary mixture with rice bran oil and pumpkin seed oil (PSO)

\begin{tabular}{|c|c|c|c|c|c|c|}
\hline \multirow{2}{*}{$\begin{array}{l}\text { Multivariate } \\
\text { calibrations }\end{array}$} & \multirow{2}{*}{ Wavenumber $\left(\mathrm{cm}^{-1}\right)$} & \multirow{2}{*}{ Spectra } & \multicolumn{2}{|c|}{ Calibration } & \multicolumn{2}{|c|}{ Validation } \\
\hline & & & $\mathrm{R}^{2}$ & RMSEC & $\mathrm{R}^{2}$ & RMSEP \\
\hline \multirow{18}{*}{ PCR } & \multirow{3}{*}{$3100-663$} & normal & 0.9972 & 0.0122 & 0.9932 & 0.0234 \\
\hline & & derivative 1 & 0.997 & 0.0125 & 0.9964 & 0.0209 \\
\hline & & derivative 2 & 0.9791 & 0.0328 & 0.9781 & 0.0368 \\
\hline & \multirow{3}{*}{$1800-663$} & normal & 0.9973 & 0.0119 & 0.994 & 0.0337 \\
\hline & & derivative 1 & 0.9958 & 0.0148 & 0.9952 & 0.0228 \\
\hline & & derivative 2 & 0.9801 & 0.0321 & 0.979 & 0.0335 \\
\hline & \multirow{3}{*}{$3100-2750$} & normal & 0.9937 & 0.0181 & 0.9939 & 0.0193 \\
\hline & & derivative 1 & 0.9844 & 0.0284 & 0.9792 & 0.0351 \\
\hline & & derivative 2 & 0.8932 & 0.0727 & 0.9052 & 0.073 \\
\hline & \multirow{3}{*}{$1500-663$} & normal & 0.9947 & 0.0166 & 0.992 & 0.0213 \\
\hline & & derivative 1 & 0.9879 & 0.025 & 0.9886 & 0.0245 \\
\hline & & derivative 2 & 0.9656 & 0.042 & 0.9681 & 0.0408 \\
\hline & \multirow{3}{*}{$3100-2750$ and $1800-663$} & normal & 0.9974 & 0.0116 & 0.9933 & 0.0252 \\
\hline & & derivative 1 & 0.9972 & 0.0122 & 0.9968 & 0.0216 \\
\hline & & derivative 2 & 0.9812 & 0.0312 & 0.9809 & 0.0325 \\
\hline & \multirow{3}{*}{$3100-2750$ and $1500-663$} & normal & 0.9927 & 0.0194 & 0.9843 & 0.0286 \\
\hline & & derivative 1 & 0.9912 & 0.0214 & 0.9914 & 0.022 \\
\hline & & derivative 2 & 0.9691 & 0.0399 & 0.9679 & 0.0415 \\
\hline \multirow{18}{*}{ PLS } & \multirow{3}{*}{$3100-663$} & normal & 0.9998 & 0.0032 & 0.997 & 0.0245 \\
\hline & & derivative 1 & 0.9999 & 0.0019 & 0.9978 & 0.021 \\
\hline & & derivative 2 & 0.9999 & 0.0021 & 0.9914 & 0.0246 \\
\hline & \multirow{3}{*}{$1800-663$} & normal & 0.9981 & 0.0098 & 0.9945 & 0.0332 \\
\hline & & derivative 1 & 0.9993 & 0.0062 & 0.9974 & 0.0258 \\
\hline & & derivative 2 & 0.9996 & 0.0146 & 0.9942 & 0.0209 \\
\hline & \multirow{3}{*}{$3100-2750$} & normal & 0.9947 & 0.0166 & 0.9952 & 0.0175 \\
\hline & & derivative 1 & 0.9955 & 0.0154 & 0.9767 & 0.0364 \\
\hline & & derivative 2 & 0.9616 & 0.0444 & 0.9363 & 0.0595 \\
\hline & \multirow{3}{*}{$1500-663$} & normal & 0.9989 & 0.0076 & 0.9935 & 0.0208 \\
\hline & & derivative 1 & 0.9943 & 0.0173 & 0.9946 & 0.0171 \\
\hline & & derivative 2 & 0.9713 & 0.0384 & 0.9736 & 0.0371 \\
\hline & \multirow{3}{*}{$3100-2750$ and $1800-663$} & normal & 0.998 & 0.0101 & 0.9943 & 0.0253 \\
\hline & & derivative 1 & 0.9993 & 0.0058 & 0.9982 & 0.0229 \\
\hline & & derivative 2 & 0.9999 & 0.0024 & 0.9954 & 0.0194 \\
\hline & \multirow{3}{*}{$3100-2750$ and $1500-663$} & normal & 0.9993 & 0.0058 & 0.9968 & 0.0211 \\
\hline & & derivative 1 & 0.9951 & 0.0159 & 0.9938 & 0.0189 \\
\hline & & derivative 2 & 0.978 & 0.0337 & 0.9785 & 0.0337 \\
\hline
\end{tabular}

*the selected condition was marked with bold.

and $1500-663 \mathrm{~cm}^{-1}$ using the second derivative FTIR spectra along with residual analysis [2B]. Residual analysis is the difference between the actual and predicted value to see the error patterns. It is clear that systematic error is negligible because all point difference falls above and below zero value. Similarly, Table 3 and Table 4 showed the statistical parameters of PLSR and PCR for prediction of RBO and SEO in ternary mixtures.

Similarly, based on the highest $\mathrm{R}^{2}$ and the lowest values of RMSEC and RMSEP, FTIR spectra using second derivate at wavenumbers of $3100-650 \mathrm{~cm}^{-1}$ was used for prediction of RBO in ternary mixtures with SEO and PSO (Table 3). While, FTIR spectra at the same wavenumbers region using the first derivative mode was preferred for quantitative analysis of sesame oil (SEO) in ternary mixture with rice bran oil and pumpkin seed oil (PSO), as compiled in Table 4.

\section{Conclusion}

The combination of FTIR spectroscopy with PLSR could be used successfully for quantitative analysis of PSO, SEO, and RBO in ternary mixtures with acceptable accuracy and precision, as indicated by the high value of $\mathrm{R}^{2}$ and low value of errors obtained. The developed method was valid and could be an effective analytical technique for quality assurance of functional oils due to its property as a fingerprint analytical method. The method also did not involve the use of extensive reagents and solvents, therefore, could be considered as a green analytical technique.

\section{Conflict of Interest}

Authors declare no conflict of interest. 


\section{Acknowledgement}

The authors thank the Ministry of Research, Technology and Higher Education, Republic Indonesia for financial support during this study through Hibah Penelitian Dasar Unggulan Perguruan Tinggi (PUPT) 2019 with contract number 2519/UN1.DITLIT/DIT-LIT/ LT/2019.

\section{References}

Armenta, S., Garrigues, S. and de la Guardia, M. (2007). Determination of edible oil parameters by near infrared spectrometry. Analytica Chimica Acta, 596 (2), 330-337. https://doi.org/10.1016/ j.aca.2007.06.028

Cuco R.P., Cardozo-Filho, L. and da Silva, C. (2019). Simultaneous extraction of seed oil and active compounds from peel of pumpkin (Cucurbita maxima) using pressurized carbon dioxide as solvent. The Journal of Supercritical Fluids, 143, 8 15. https://doi.org/10.1016/j.supflu.2018.08.002

Elfiky, S.A., Elelaimy, I.A., Hassan, A.M., Ibrahim, H.M. and Elsayad R.I. (2012). Protective effect of pumpkin seed oil against genotoxicity induced by azathioprine. The Journal of Basic and Applied Zoology, 65(5), 289-298. https://doi.org/10.1016/ j.jobaz.2012.10.010

Fruhwirth, G.O., Wenzl, T., El-Toukhy, R., Wagner, F.S. and Hermetter, A. (2003). Fluorescence screening of antioxidant capacity in pumpkin seed oils and other natural oils. European Journal of Lipid Science and Technology, 105(6), 266-274. https:// doi.org/10.1002/ej1t.200390055

Fu, C., Shi, H. and Li, Q. (2006). A review on pharmacological activities and utilization technologies of pumpkin. Plant Foods for Human Nutrition, 61, 73-80.

Ghosh, M. (2007). Review on recent trends in rice bran oil processing. Journal of the American Oil Chemists' Society, 84(4), 315-324. https:// doi.org/10.1007/s11746-007-1047-3

Irnawati, Riyanto, S., Martono, S. and Rohman, A. (2020), The employment of FTIR spectroscopy and chemometrics for authentication of pumpkin seed oil from sesame oil. Food Research, 4(1), 42-48. https:// doi.org/10.26656/fr.2017.4(1).198

Ji, J., Liu, Y., Shi, L., Wang, N. and Wang, X. (2019). Effect of roasting treatment on the chemical composition of sesame oil. LWT - Food Science and Technology, 101, 191-200. https://doi.org/10.1016/ j.lwt.2018.11.008

Liu, R., Liu, R., Shi, L., Zhang, Z., Zhang, T., Lu, M., Chang, M., Jin, Q. and Wang, X. (2019). Effect of refining process on physicochemical parameters, chemical compositions and in vitro antioxidant activities of rice bran oil. LWT - Food Science and Technology, 109, 26-32. https://doi.org/10.1016/ j.lwt.2019.03.096

Miyawaki, T., Aono, H., Toyoda-Ono, Y., Maeda, H., Kiso, Y. and Moriyama, K. (2009). Antihypertensive effects of sesamin in humans. Journal of Nutrition Science and Vitaminology, 55(1), 87-91. https:// doi.org/10.3177/jnsv.55.87

Mosayebi, G., Ghazavi, A., Salehi, H., Payani, M.A. and Khazae, M.R. (2007). Effect of sesame oil on the inhibition of experimental autoimmune encephalomyelitis in C57BL/6 mice. Pakistan Journal of Biology Science, 10(11), 1790-1796. https:// doi.org/10.3923/pjbs.2007.1790.1796

Nahar, L. and Rokonuzzaman. (2009). Investigation of the analgesic and antioxidant activity from an ethanol extract of seeds of Sesamum indicum. Pakistan Journal of Biology Science, 12(7), 595-598. https:// doi.org/10.3923/pjbs.2009.595.598

Nakano, D., Ogura, K., Miyakoshi, M., Ishii, F., Kawanishi, H., Kurumazuka, D., Kwak, C.J., Ikemura, K., Takaoka, M., Moriguchi, S., Iino, T., Kusumoto, A., Asami, S., Shibata, H., Kiso, Y. and Matsumura, Y. (2006). Antihypertensive effect of angiotensin Iconverting enzyme inhibitory peptides from a sesame protein hydrolysate in spontaneously hypertensive rats. Bioscience, Biotechnology and Biochemistry, 70(5), 1118-1126. https://doi.org/10.1271/bbb.70.1118

Nakano, D., Kwak, C.J., Fujii, K., Ikemura, K., Satake, A., Ohkita, M., Takaoka, M., Ono, Y., Nakai, M., Tomimori, N., Kiso, Y. and Matsumura, Y. (2006). Sesamin metabolites induce an endothelial nitric oxidedependent vasorelaxation through their antioxidative property-independent mechanisms: possible involvement of the metabolites in the antihypertensive effect of sesamin. Journal of Pharmacology and Experimental Therapeutics, 318(1), 328-335. https:// doi.org/10.1124/jpet.105.100149

Nawirska-Olszan' ska, A., Kita, A., Biesiada, A., SokółŁe, Towska, A. and Kucharska, A.Z. (2013). Characteristics of antioxidant activity and composition of pumpkin seed oils in 12 cultivars. Food Chemistry, 139(1-4), 155-161. https:// doi.org/10.1016/j.foodchem.2013.02.009

Naziri, E., Mitić, M.N. and Tsimidou, M.Z. (2016). Contribution of tocopherols and squalene to the oxidative stability of cold-pressed pumpkin seed oil. European Journal of Lipid Science and Technology, 118(6), 898-905. https://doi.org/10.1002/ ejlt.201500261

Nishimura, M., Ohkawara, T., Sato, H., Takeda, H. and 
Nishihira, J. (2014). Pumpkin Seed Oil Extracted from Cucurbita maxima Improves Urinary Disorder in Human Overactive Bladder. Journal of Traditional and Complementary Medicine, 4(1), 72-74. https://doi.org/10.4103/2225-4110.124355

Patel, M. and Naik, S.N. (2004). Gamma-Oryzanol from rice bran oil-A review. Journal of Scientific and Industrial Research, 63(7), 569-578.

Rao, Y.P., Sugasini, D. and Lokesh, B.R. (2016). Dietary gamma oryzanol plays a significant role in the antiinflammatory activity of rice bran oil by decreasing proinflammatory mediators secreted by peritoneal macrophages of rats. Biochemical and Biophysical Research Communications, 479(4), 747-752. https:// doi.org/10.1016/j.bbrc.2016.09.140

Ramesh, B., Saravanan, R. and Pugalendi, K. (2005). Influence of sesame oil on blood glucose, lipid peroxidation, and antioxidant status in streptozotocin diabetic rats. Journal of Medicinal Food, 8, 377381. https://doi.org/10.1089/jmf.2005.8.377

Rohman, A. and Che Man, Y.B. (2011a). Potential Use of FTIR-ATR Spectroscopic Method for determination of virgin coconut oil and extra virgin olive oil in ternary mixture systems. Food Analytical Methods, 4(2), 155-162. https:// doi.org/10.1007/s12161-010-9156-2

Rohman, A. and Che Man, Y.B. (2011b). Determination of extra virgin olive oil in quaternary mixture using FTIR spectroscopy and multivariate calibration. Journal of Spectroscopy, 26(3), 203-211. https:// doi.org/10.1155/2011/471376

Rohman, A. and Che Man, Y.B. (2010). FTIR spectroscopy combined with chemometrics for analysis of lard in the mixtures with body fats of lamb, cow, and chicken. International Food Research Journal, 17, 519-526.

Sim, S.F. and Ting, W. (2012). An automated approach for analysis of Fourier Transform Infrared (FTIR) spectra of edible oils. Talanta, 88, 537-543. https:// doi.org/10.1016/j.talanta.2011.11.030

Thanonkaew, A., Wongyai, S., McClements, D.J. and Decker, E.A. (2012). Effect of stabilization of rice bran by domestic heating on mechanical extraction yield, quality, and antioxidant properties of coldpressed rice bran oil (Oryza saltiva L.). LWT - Food Science and Technology, 48(2), 231-236. https:// doi.org/10.1016/j.lwt.2012.03.018

Wilson, T.A., Nicolosi, R.J., Woolfrey, B. and Kritchevsky, D. (2007). Rice bran oil and oryzanol reduce plasma lipid and lipoprotein cholesterol concentrations and aortic cholesterol ester accumulation to a greater extent than ferulic acid in hypercholesterolemic hamsters. Journal of Nutritional Biochemistry, 18(2), 105-112. https:// doi.org/10.1016/j.jnutbio.2006.03.006

Yoshiyukimiyahara, H.H., Katsuzaki, H., Mai, K. and Komiya, T. (2001). Sesamolin from sesame seed inhibits proliferation by inducing apoptosis in human lymphoid leukemia Molt 4B cells. International Journal of Molecular Medicine and Advanced Science, 7(4), 369-371. https://doi.org/10.3892/ ijmm.7.4.369

Zuhair, H.A., Abd El-Fattah, A.A. and El-Sayed, M.I. (2000). Pumpkin-seed oil modulates the effect of feloipine and captopril in spontaneously hypersensitive rats. Pharmacology Research, 41(5), 555-563. https://doi.org/10.1006/phrs.1999.0622 